\title{
Persistence of oral anticoagulants in japanese patients with atrial fibrillation: non-vitamin $k$ antagonist oral anticoagulant versus warfarin
}

Tsuyoshi Shiga*

Department of Cardiology, Tokyo Women's Medical University, Tokyo, Japan

*Author for correspondence:

Tel.: +81333538111

mshiga@hij.twmu.ac.jp form of tachyarrhythmia and a wellknown stroke risk [1-4]. Many studies have demonstrated that vitamin $\mathrm{K}$ antagonists such as warfarin reduce the incidence of stroke in AF patients $[4,5]$. In a "real world" setting, however, a US cohort study showed that one-fourth of patients initiating warfarin for the first time for AF discontinued treatment within the first year [6]. Adherence to longterm anticoagulation therapy is a key for the prevention of stroke in at-risk AF patients. Since the approval of dabigatran by the U.S. Food and Drug Administration (FDA) in 2010, and in Japan in 2011, non-vitamin $\mathrm{K}$ antagonist oral anticoagulants (NOACs) have appeared in clinical practice. Large-scale randomized clinical trials (RCTs) assessing their application have shown NOACs to be as safe and effective as warfarin in patients with non-valvular AF (NVAF). Adherence to medication in RCTs is often high because selected patients are enrolled in these studies and patient adherence is attentively monitored [7].

As reported in our previous study, there was a significantly lower rate of NOAC treatment persistence compared to warfarin treatment persistence in Japanese patients with NVAF [8]. A meta-analysis of RCTs reported that the discontinuation rates of NOACs, warfarin and aspirin for the prevention of stroke in AF patients were not significantly different [9]. A cohort study of NVAF patients in the US found that the persistence rate of patients who were prescribed warfarin was lower than that of patients who were prescribed dabigatran [10]. This cohort's 12-month persistence rate for dabigatran was $63.3 \%$, and a cohort of patients in Dresden had 12-month persistence rates for dabigatran and ribaroxaban of approximately $75 \%$ and $85 \%$, respectively [10-12]. The persistence rates for NOACs in our study (dabigatran, $66.0 \%$; ribaroxaban, $65.7 \%$; and apixaban, $81.4 \%$ ) are comparable to these results, but the persistence rate for warfarin $(88.4 \%)$ in our study was higher than those in the US cohort studies [10,13-16].

Although the reason for this difference is unclear, it may be partially due to differences in the medical care systems (e.g., in the number of regular cardiology visits at outpatient clinics and in patient adherence to warfarin by frequent assessments of prothrombin time-international normalized ratio (PT-INR) values and subsequent dose adjustments as needed). This may also mean that the time in the therapeutic range (TTR) in generally higher in Japan than other countries $[17,18]$. The previous Japanese guideline for pharmacotherapy of AF (JCS 
2008) recommended that the PT-INR be monitored at least weekly during induction of warfarin therapy and at least monthly after achieving a stable PT-INR (class I) [19]. Therefore, Japanese physicians usually check the PT-INR and frequently adjust doses accordingly, leading to a high TTR. These actions may enhance patient awareness of anticoagulation and therefore their adherence to warfarin therapy.

Several factors, including those related to the patient, the drug, the disease, and the patient-physician relationship, affect adherence to medication. In practice, we recognize some barriers to adherence. In our study, the most common reason for discontinuation

\section{References}

1. Feinberg WM, Blackshear JL, Laupacis A, Kronmal R, Hart RG. Prevalence, age distribution, and gender of patients with atrial fibrillation. Analysis and implications. Arch. Intern. Med. 155, 469-473 (1995).

2. Go AS, Hylek EM, Phillips KA, et al. Prevalence of diagnosed atrial fibrillation in adults: national implications for rhythm management and stroke prevention: the AnTicoagulation and Risk Factors in Atrial Fibrillation (ATRIA) Study. JAMA. 285, 2370-2375 (2001).

3. Wolf PA, Abbott RD, Kannel WB. Atrial fibrillation as an independent risk factor for stroke: the Framingham Study. Stroke 22, 983-988 (1991).

4. Atrial Fibrillation Investigators. Risk factors for stroke and efficacy of antithrombotic therapy in atrial fibrillation. Analysis of pooled data from five randomized controlled trials. Arch. Intern. Med. 154, 1449-1457 (1994).

5. Hart RG, Pearce LA, Aguilar MI. Meta-analysis: antithrombotic therapy to prevent stroke in patients who have nonvalvular atrial fibrillation. Ann. Intern. Med. 146, 857-867 (2007).

6. Fang MC, Go AS, Chang Y, et al. Warfarin discontinuation after starting warfarin for atrial fibrillation. Circ. Cardiovasc. Qual. Outcomes. 3, 624-631 (2010).

7. Osterberg L, Blaschke T. Adherence to medication. N. Engl. J. Med. 353: 487-497 (2005).

8. Shiga T, Naganuma M, Nagao T, et al. Persistence of nonvitamin $\mathrm{K}$ antagonist oral anticoagulant use in Japanese patients with atrial fibrillation: A single-center observational study. J. Arrhythm. 31: 339-344 (2015).

9. Chatterjee S, Sardar P, Giri JS, Ghosh J, Mukherjee D. Treatment discontinuations with new oral agents for longterm anticoagulation: insights from a meta-analysis of 18 randomized trials including 101,801 patients. Mayo. Clin. Proc. 89, 896-907 (2014)

10. Zalesak M, Siu K, Francis K, et al. Higher persistence in newly diagnosed nonvalvular atrial fibrillation patients treated with dabigatran versus warfarin. Circ. Cardiovasc. Qual. Outcomes. 6: 567-574 (2013). of NOAC treatment was the occurrence of adverse events, including bleeding events; this was similar to the findings for the Dresden cohort $[8,11,12]$. Minor bleeding associated with anticoagulation therapy is often observed but is not a predictor of major bleeding [20]. Moreover, cultural backgrounds affect patient behavior and adherence. In particular, Japanese patients tend to be more distressed by drug side effects than they are by ineffective drugs. Patient preference as well as patient education and understanding of the treatment are important factors in adherence to anticoagulation therapy in NVAF patients.

11. Beyer-Westendorf J, Ebertz F, Förster K, et al. Effectiveness and safety of dabigatran therapy in daily-care patients with atrial fibrillation. Results from the Dresden NOAC Registry. Thromb. Haemost. 113: 1247-1257 (2015).

12. Beyer-Westendorf J, Förster K, Ebertz F, et al. Drug persistence with rivaroxaban therapy in atrial fibrillation patients-results from the Dresden non-interventional oral anticoagulation registry. Europace. 17, 530-538 (2015).

13. Gallagher AM, Rietbrock S, Plumb J, van Staa TP, Initiation and persistence of warfarin or aspirin in patients with chronic atrial fibrillation in general practice: do the appropriate patients receive stroke prophylaxis? J. Thromb. Haemost. 6, 1500-1506 (2008)

14. Fang MC, Go AS, Chang Y, et al. Warfarin discontinuation after starting warfarin for atrial fibrillation. Circ. Cardiovasc. Qual. Outcomes. 3, 624-631 (2010).

15. Gomes T, Mamdani MM, Holbrook AM, Paterson JM, Juurlink DN. Persistence with therapy among patients treated with warfarin for atrial fibrillation. Arch. Intern. Med. 172, 1687-1689 (2012)

16. Martinez C, Katholing A, Wallenhorst C, Freedman SB. Therapy persistence in newly diagnosed non-valvular atrial fibrillation treated with warfarin or NOAC. A cohort study. Thromb. Haemost. 115: 31-39 (2016).

17. Naganuma M, Shiga T, Sato K, et al. Clinical outcome in Japanese elderly patients with non-valvular atrial fibrillation taking warfarin: a single-center observational study. Thromb. Res. 130, 21-26 (2012).

18. Okumura K, Komatsu T, Yamashita T, et al. Time in the Therapeutic Range During Warfarin Therapy in Japanese Patients With Non-Valvular Atrial Fibrillation - A Multicenter Study of Its Status and Influential Factors. Circ. J. 75, 2087-2094 (2011).

19. JCS Joint Working Group. Guidelines for pharmacotherapy of atrial fibrillation (JCS 2008): digest version. Circ. J. 74, 24792500 (2010).

20. Beyer-Westendorf J, Förster K, Pannach S, et al. (2014) Rates, management, and outcome of rivaroxaban bleeding in daily care: results from the Dresden NOAC registry. Blood. 124, 955-962. 